\title{
Education Is an Important Factor of Human Capital Development in Rural Territories
}

\author{
Svetlana Golovina ${ }^{1, *}$, Lidia Smirnova ${ }^{2}$, and Aleksey Ruchkin ${ }^{1}$ \\ ${ }^{1}$ Ural state agrarian University, Institute of Economics, Finance and Management, 620075 ul. Karl \\ Liebknecht, 42, Yekaterinburg, Russia \\ ${ }^{2}$ Kurgan State Agricultural Academy, 641300 Lesnikovo village, Ketovsky district, Russia
}

\begin{abstract}
The article presents conceptual ideas concerning the state of the lifelong learning system of direct relevance to domestic (Russian) rural areas. Based on the analysis of scientific literature and summarizing the various points of view of scientists and practitioners on this issue, first, it reveals some reasons for the current disproportions in the labor market (unemployment on the one hand, and the lack of specialists on the other hand) and not quite effective operation of institutional structures of all types of education (general, vocational, additional), second, it specifies the main directions of educational reforms, the implementation of which will provide rural areas with highly qualified specialists. The conclusion is made that the current conditions, the structure of the education system, supplying qualified personnel for the domestic rural space, do not adequately provide the rural economy with the human capital of the quality demanded.
\end{abstract}

\section{Introduction}

In recent years, the problems associated with the development of rural areas, both in Russia and in other countries, have become increasingly relevant. According to the results of many socio-economic studies, the key factor in their solution is human capital, the relevance of the quantity, structure and quality of which provides (1) the effective use of the resource potential available within the boundaries of rural areas, (2) the revival of the rural economy and harmonious development of territories and communities, (3) innovative development of a particular region, its competitiveness, (4) favourable social and environmental conditions for the life of the resident population. However, the improvement of human capital in rural areas is impossible without the formation of the educational system adequate to the new realities and requirements, one of the main postulates of which in the conditions of modern internal and external challenges (scientific and technical innovations, globalization, unstable political environment, technospheric anomalies, biological threats) is continuity («education through life»).

\footnotetext{
* Corresponding author: s_golovina@yahoo.com
} 


\section{Method}

The authors of the scientific term «human capital» (T. Schultz, G. Becker, J. Minzer, L. Thurow), who founded, in fact, the theory of human capital, identify a set of knowledge, skills, abilities (which the employee brings to the company) as one of the varieties of capital $[1,2]$. It is argued that human capital (as any other) is the result of investment (in education, professional training), determining the increase in the production of goods and services (improvement of their quality indicators), the growth of individual income, obtaining other private and public benefits [3]. Emphasizing the dependence of people's welfare not on land and technology, but mainly on specialized knowledge, the classics of this approach consider education to be an integral part of human life, a source of formation and development of personal qualities used by people in their life activities [4].

Specifying the scientists' views on the role of human capital in general and education in particular, we note that T. Schultz, for example, specifies the place of education in the content of human capital and its importance in society as follows: 1) workers invest in education, knowledge and skills, expecting an increase in wages due to higher professional characteristics; 2) financial investments in education allow employees not only to satisfy their immediate needs, but also, by deriving added value, to continue investing in improving their human capital and, of course, their quality of life; 3) companies also invest in education and professionalism of employees, knowing that the return on them will be $b$ In turn, developing the theory of human capital, G. Becker scientifically proves that education and training significantly increase employee productivity by providing valuable knowledge and skills, although, of course, the amount of future earnings may depend on other factors (health, life expectancy and many others) [2].

In general, focusing on human capital (including that integrated with other forms of capital), scientists emphasize the high importance of education and, consequently, public policy in this area for long-term economic growth and dynamic development of society [5, 6]. Guided by this scientific approach and the results of its practical application, the state invests certain funds in this sector of the economy, improving the education system so that its products (human capital carriers, first of all) would have qualities that correspond to the preferences of individuals, employers' criteria and social priorities. Nevertheless, at present at all levels (international, federal, regional) scientific and political discussions continue concerning (1) established asymmetry between the rate of scientific and technological progress and the dynamics of changes in education and training, (2) established mismatch between the human capital available within the borders of territories (regions, countries) and the requirements imposed on it by economy and society, mainly by business representatives. In their opinion, the shortage of competent workers prevents the introduction of new highly productive technologies and, as a consequence, affects the success of both large industrial enterprises (and the corresponding urbanised areas) and small agricultural organisations (and the surrounding rural areas).

Globally, however, the mismatch between supply and demand for human capital (knowledge, skills, abilities) at the level of individual (sectoral) labour markets, on the scale of specific entities, and within the national economy as a whole becomes a significant problem. At the same time, under market conditions (when supply and demand must be balanced by the price mechanism) the disproportions are becoming more acute, and the theoretical algorithm of the classical market in this segment (labour market) shows high inertness and «sluggishness». As a result, the level of education is not always correlated with income, and the economy faces both unemployment and lack of specialists in certain professions (categories), which is caused (besides demographic processes) either by insufficient education (low level of formed competencies) or its excessiveness (unclaimed unique knowledge and other human capital attributes) [7]. 
As for the problem of labour shortage, some scholars link it to such negative circumstances as (1) population ageing in many (especially developed) countries, (2) lower growth rate of working-age population, (3) onset of certain phases of business cycle (revival, recovery), when rapidly growing economy requires an adequate expansion of labour force, (4) transition of scientific and technological progress to a fundamentally new quality, which requires appropriate features of human capital, (5) formation of a new (under the influence of various challenges) economic structure, with which the existing composition of human capital enters into a noticeable resonance [8]. The solution to this problem could be a reciprocal (equally rapid) transformation of the education system, taking into account all the changes taking place in the economy and society. However, based on retrospective studies and practical experience, it can be concluded that educational reforms are taking place with a significant lag, thus hindering positive changes in the content of human capital. Based on the above, the purpose of this study is related to the system of lifelong learning, which provides personnel for rural territories, namely (1) studying its role in the development of rural areas (their human capital), (2) identifying the existing problems in its development, (3) identifying promising trajectories of its improvement.

\section{Study details and results}

All levels of education are important in the formation of human capital of the quality demanded, for example, in Russia - general education, vocational education, additional education, vocational training. As the research results and many years of experience in the field of higher education show, entrepreneurs (employers) have complaints about the quality of education in general. Thus, dissatisfaction with general education is argued by the lack of basic skills that school leavers need to perform jobs that do not require special vocational training. According to employers, modern state standards, covering many competences (most of which remain unclaimed), do not guarantee successful employment of boys and girls directly after general education.

The next focus of claims is on the content of secondary vocational education, which has been weakened in many countries in favour of white collar training. In fact, the automation and robotization processes in many sectors of the economy are being held back by a shortage of skilled workers, for which there are problems both in terms of training procedures (time required, appropriate facilities, etc.) and in terms of mentality (administrative and managerial positions are preferred).

In the sphere of higher education against the background of the deficit in the regions (including rural areas) of a wide range of narrow specialists (doctors, teachers, agronomists, etc.) the illusion of insufficient education of the population living in this or that territory is created. However, for modern science and practice (along with the lack of professionals and low qualification level of employees) the opposite problem is more significant - excessive (excessive) education, the return from which for individual employees with a higher (relative to the required for the tasks) level of training does not correspond to the formed expectations [9]. As a result, the losses at the individual level are measured by the inefficient costs of the individual in the course of training, at the company level by the need (under pressure of the employee) to pay higher wages (and not for the complexity and quality of work performed, but for the formal qualification of the employee), at the society level by the costs of education, which, in fact, turns out to be unclaimed.

Let us note that the manifestation of excessive education is not so much the availability of specialists with unique (currently unclaimed) training, as the situation established in the world practice (including Russia), when most school graduates, taking advantage of the wide availability of higher education (availability of a large number of budget places, low 
admission requirements in case of commercial education), seek to obtain it compulsory, not having the necessary potential. On the other hand, upon entering industry, graduates expect lucrative offers (prestigious positions, high salaries), but do not always match the required qualifications, resulting in private costs (wasted individual time and money on training, moral and material dissatisfaction), and public costs (unjustified public expenditure on the education of those who do not occupy the jobs according to the National Education Act). In response to the existing circumstances, the effects of excessive education (overqualification) have been studied by representatives of various scientific disciplines and trends over the last few decades [9], with the following consequences highlighted as negative: (1) dissatisfaction of employees, (2) their reluctance to invest in their further professional and personal development, (3) dissatisfaction of employers who have to raise wages for unclaimed (although possibly unique) knowledge and skills, (4) disappointment of the society with the current discrepancy between the structure of human capital formed (including through tax-funded education) and the demand for it in the economy.

Additional education is an important component of modern lifelong learning, which, under favourable conditions (including good organisation), is designed to correct market failures caused both by the state of the economy and the education system as a whole. Of course, the ideal situation for employers is when applicants come to the company with exactly the number of competences needed to perform certain tasks, without requiring additional training. From the point of view of business, the obligations in respect of additional education of specialists, advanced training and re-training should be placed (1) on state educational institutions which should not only train graduates with the competences in demand, but also provide them with opportunities for further education and training, (2) on the employees themselves who are most interested in developing their human capital for a successful career and income growth.

There is another point of view according to which the task of adapting employees' competences (and other aspects of human capital) to new production requirements even conceptually should be addressed directly to the employer. When employing a workforce, it is the employer's responsibility to train and develop employees throughout their employment, meeting the specific (rapidly changing) needs of production in knowledge, skills, and abilities. Science and practice have a comprehensive argument for this: 1) not all employees have the financial capacity to invest in future (risky) earnings; 2) the requirements of employers can be so specific that only they can arrange training according to production needs; 3 ) many skills are easier and cheaper to learn on the job using modern training technologies. And yet, analyzing the educational opportunities of the residents of rural areas engaged in agricultural production, we note that only one in ten professionals acquires any new professional skills at the initiative of the employer, although the heads of farms in the conducted surveys constantly express their complaints about the initial training of personnel [10].

As a result, poor planning in public education and inflexibility in the activities of commercial educational structures become the main reasons for significant disproportions in the structure of personnel training, expressed, for example, in the era of transition to a market economy, on the one hand, by a saturation (in rural areas as well) of economists and lawyers, on the other hand, by a significant deficit of engineers, agronomists, teachers and doctors. Moreover, many university graduates (according to the survey) do not plan to work in their profession at all, as their choice of university or specialty was not purposeful. This problem is especially acute for agrarian universities, which train specialists for agriculture and rural areas, because only $25 \%$ of graduates are employed according to their qualification, while in rural areas there are vacancies for agronomists, zootechnicians, veterinarians, etc. (for a number of years). According to the results of the survey of graduates, most of them (especially those coming from rural families) link their choice to 
study in agricultural higher education institutions not with the need to work in agriculture, but mainly with certain socio-economic conditions (convenient location of the university, low tuition fees, low cost of living, acceptable passing grades, limited income of parents). In addition, not all graduates of agrarian universities (in Kurgan State Agricultural Academy their number is about $71 \%$ ) agree to take up vacant positions with the salary offered by employers, and most farm managers are not ready to increase it.

It should be emphasized that the classical market model of education is not characterized by such phenomena as labor shortage and surplus. Theoretically, an equilibrium follows the well-known algorithm when employers (1) hire those whose wage expectations (given the identity of the required and the available competences) do not exceed the level declared by the company, (2) increase wages in the case when it is necessary to attract more competent candidates, (3) innovate and adopt more efficient work methods which match the qualifications of the employees, (4) replace some of the technological operations performed by workers (human capital) with processes performed by technical means (physical capital). Undoubtedly, the education systems of many countries are permanently adapting and trying to conform to this algorithm. At the same time, scholars investigating the causes of labor market imbalances attribute them to (1) inelastic wages (moreover, their freezing during extraordinary periods), (2) restrictions on labor mobility (again, caused by shocks and unique circumstances) not attributable to the market, (3) specific rural conditions, (4) economic crises, (5) natural disasters, (6) epidemics and pandemics. As a result, each of the identified causes determines to a greater or lesser extent certain reforms in education.

Summarizing the above, we emphasize that the main problem of the education sphere scientists and practitioners reduce to the fact that the current educational system in a completely new institutional environment trains «specialists of the past», providing them with obsolete (inefficient) intellectual tools, «sending them to work, which by the end of their education practically does not exist» [11]. This fact explains, first, the high percentage of the unemployed, and second, the dissatisfaction of business with the quality of human capital available to it. In this regard, fundamental studies of possible trajectories of education development, which define for policy makers and practitioners the conceptual basis for reforms aimed at the development of human capital of the required quality, are becoming increasingly relevant.

For example, with regard to general education, the focus should be on the development of basic skills that are in demand in all spheres and, of course, on the cultivation of special personal qualities that are important to society and business. In the context of economic transition to a fundamentally new state (knowledge economy), diligence and conscientiousness, critical thinking and creativity, the ability to work in a team and make decisions are of particular value. Entrepreneurship, self-learning, leadership and communication skills are fully encouraged and motivated. In order to improve all these skills and consequently increase the opportunities for further (after school) employment or successful vocational training, it is advisable to (1) improve the quality of education, (2) develop special mechanisms (institutions) of convergence between general education schools (students) and business organizations (employers). In practice, this means encouraging mentoring, apprenticeships, developing and implementing cooperative programs, organizing internships and other activities that help students to see the practical value of their training.

As far as vocational education and training (higher education, above all) is concerned, the comprehensive transformations taking place are no less significant (both academically and practically). On the one hand, significant changes are taking place in the management, organization and content of higher education institutions due to their evident orientation towards research and development activities. On the other hand, the structure and content of 
graduate training is largely determined by the practical preferences of business, which puts more professional than academic demands on its participants. Thus, a survey of hiring managers conducted by American scientists back in 2011 showed that out of 15 attributes listed as important for the success of organizations, academic knowledge, skills and abilities were on the last positions, and purely applied competences came to the fore [12].

Of course, the main factor that determines and structures the list of in-demand professions is scientific and technological progress that generates new industries (new types of work) and acts as a driver of «natural selection» in the list of in-demand qualifications. It is in line with these processes (digitalization of the economy, robotics of production, introduction of artificial intelligence) and the introduction of new technologies (information and communication technologies, nanotechnology, biomedical technologies of life support and human protection, technologies of new and renewable energy sources, etc.) that fundamentally new qualifications and specialties appear, forcing recently sought-after and popular ones out of the labor market. For example, today (with a shortage of various narrow professionals) almost every sector feels an acute shortage of IT specialists, which requires, firstly, expanding training of personnel with such qualifications, and secondly, creating special conditions for their work. For rural areas this problem is particularly difficult, but at the same time urgent. In fact, virtual technologies are becoming a reality of agricultural production, and the creation of living conditions for IT specialists (including decent pay for their work) is mainly within the power of successfully developing farms.

Supplementary education in the current (fluctuating, sometimes turbulent) environment is also given special importance. In fact, the properly organized functioning of this element of the education system is capable of correcting many deficiencies (disproportions, asymmetry in relation to the real economy) of the educational process as a whole. Directly through additional training, requalification and complementary vocational training, opportunities (1) to get a highly sought-after specialist for business, (2) to realize their desires, abilities and talents for each member of society, in which regard employers and employees alike should have an interest in the development of additional education. Moreover, identifying investment in human resources as an essential condition for the transition to highly productive technologies requiring unique skills is a task for both domestic business (including the agricultural sector) and the state education system. For the individual, learning in the process of life is both a condition for career growth (higher income), and an alternative mechanism for self-realization (moral satisfaction, development of personal abilities and preferences). Moreover, when defining the directions, tools, means and results of learning, the system of additional education should take into account the whole range of goals, participants and opportunities specified in the study. In addition, the institutions offering these services should be very diverse - universities, public services (extension services, for example), private specialists (holders of exceptional knowledge and skills) and others.

\section{Conclusion}

In conclusion, it should be noted that the problem of competence disharmony (mismatch between competences offered at employment by graduates of educational institutions and competences demanded by the economy at a particular time) has been the object of interdisciplinary research for several decades (it has been especially relevant for Russian practice in recent years). The well-known slogan «forget everything you were taught at university», which is dictated to a graduate at the time of entering employment, clearly demonstrates the entrenched problem of modern education in modern reality and public consciousness. Summarizing the abovementioned, several important conclusions should be made regarding prospective directions of lifelong learning development both in terms of its 
content and its institutionalization, in particular: 1) in the era of rapid technical and technological changes, the task of optimizing the supply (quantity and quality) of educational services is solvable, but with the joint efforts of government, business, population; 2) during the improvement of education system it is necessary to simultaneously consider globalization of all spheres of social life, individualization of business processes and personalization of individuals' life activities (their potential and preferences) 3) The existing system of education, based on universal accessibility and mass nature, has exhausted itself, resulting in low efficiency of investment in this area by the state and by students; therefore, changes in all elements of the educational system are expedient and inevitable; 4) New phenomena (digitalization of economy, spread of artificial intelligence, discovery of new types of resources, etc.) significantly change the structure of demand. 4) new phenomena taking place (digital economy, the spread of artificial intelligence, the discovery of new resources, etc.) significantly change the structure of demand on the labour market, and therefore the education system should radically modify its material base, methods and results of training; 5) as the fluctuations observed in the world in politics, economics and ecology have a significant impact on the content of educational reforms, it is necessary to maximally flexible the educational system and radical changes of its elements clarification of current areas of training, adjustment of requirements for the content of training of specialists, introduction of effective tools and forms of training, etc.); 6) optimizing the structure and quality of specialists' training (and, consequently, solving the problems of «lack of competences» and «excessive education») in the current environment is impossible without harmonious incorporation of modern business structures (employers) into the education system, and therefore duality of education, which results in classical educational institutions and business companies distributing the functions of training specialists of all levels among themselves, becomes a reality. As a result, reforming the entire educational system with due regard for the abovementioned directions can ensure quality lifelong learning, forming human capital with the characteristics demanded by society.

The reported study was funded by RFBR, project number 19-29-07315.

\section{References}

1. T.W. Schultz, American Economic Review, 51, 1-17 (1961)

2. G.S. Becker, Journal of Political Economy, 70, 5 (2), 9-49 (1962)

3. T.W. Schultz, Investment in Human Capital: The Role of Education and of Research, (New York, Free Press, 1971)

4. T.W. Schultz, The Economic Value of Education, (New York, Columbia University Press., 1963)

5. B. Lenkei, G. Mustafa, M. Vecchi, Economic Modelling, 73, 240-253, (2018) DOI: 10.1016/j.econmod.2018.03.020

6. H. Xu, W.-L. Hsu, T.-H. Meen, J.H. Zhu, Sustainability, 12, 2515, (2020) DOI: $10.3390 /$ su 12062515

7. S.G. Golovina, I.N. Mikolaychik, L.N. Smirnova, Agrarian Bulletin of the Ural, 8 (199), 65-79 (2020) DOI: 10.32417/1997-4868-2020-199-8-65-79

8. R.M. López, R.M. Ytarte, B.E. Ramiro, International Journal of Adolescence and Youth, 25 (1), 35-51, (2020) DOI: 10.1080/02673843.2019.1581068

9. P. Cappelli, J.R. Keller, Industrial and Labor Relations Review, 6(4), 874-901 (2013) 
10. A. Wolz, S. Golovina, J. Nilsson, S. Hess, Outlook on Agriculture, 45(2),111-116 (2016)

11. M. Kaku, The Future of Humanity: Terraforming Mars, Interstellar Travel, Immortality, and Our Destiny Beyond Earth, (New York, Doubleday, 2018)

12. Career Advisory Board. Research Report: Career Advisory Board Job Preparedness Indicator. Presented by DeVry University, and Harris Interactive Interviewing. http://careeradvisoryboard.com/public/uploads/2011/11/Job-Preparedness-Indicator-

Research-Report.pdf. (2011) 